\title{
One-Step Synthesis of the Nitrogen and Sulfur Codoped Carbon Dots for Detection of Lead and Copper Ions in Aqueous Solution
}

\author{
Hui Gao ${ }^{1},{ }^{1,2}$ Yuqian Pang, ${ }^{2}$ Lei Li, ${ }^{1}$ Chun $\mathrm{Zhu}^{1}{ }^{1}$ Chaoqun Ma, ${ }^{1}$ Jiao Gu, ${ }^{1}$ Yamin Wu, \\ and Guoqing Chen $\mathbb{D}^{1}$ \\ ${ }^{1}$ School of Science, Jiangsu Provincial Research Center of Light Industrial Optoelectronic Engineering and Technology, \\ Jiangnan University, Wuxi 214122, China \\ ${ }^{2}$ School of Physical Science and Technology, Lanzhou University, Lanzhou 730000, China
}

Correspondence should be addressed to Hui Gao; gaohui@jiangnan.edu.cn and Guoqing Chen; cgq2098@jiangnan.edu.cn

Received 27 July 2020; Revised 12 September 2020; Accepted 29 October 2020; Published 25 November 2020

Academic Editor: Mauro Epifani

Copyright ( 2020 Hui Gao et al. This is an open access article distributed under the Creative Commons Attribution License, which permits unrestricted use, distribution, and reproduction in any medium, provided the original work is properly cited.

\begin{abstract}
Herein, by using the green and cheap L-cysteine as the precursor, nitrogen and sulfur codoped carbon dots (NS-CDs) were synthesized via a facile one-step hydrothermal method. The obtained NS-CDs showed the relatively narrow size distributions $(2.1 \sim 3.9 \mathrm{~nm})$ with the lattice spacing of $0.29 \mathrm{~nm}$, as well as the excitation-dependent photoluminescence (PL) emission activity with the quantum yield (QY) of $18 \%$. More interestingly, the PL intensity of NS-CDs was quenched by the addition of copper or lead ions $\left(\mathrm{Cu}^{2+}\right.$ or $\left.\mathrm{Pb}^{2+}\right)$, which was shown in the tradition detection method by PL spectra. The NS-CDs exhibited ultrasensitive colorimetric sensing capability for both $\mathrm{Cu}^{2+}$ and $\mathrm{Pb}^{2+}$ by the color variance using naked eyes without any further treating. Two different coupling ways for detecting $\mathrm{Pb}^{2+}$ and $\mathrm{Cu}^{2+}$ were induced by the analysis of the Fourier transform infrared spectroscopy (FT-IR) and X-ray photoelectron spectroscopy (XPS). And the as-prepared NS-CDs showed their potential application in the heavy metal ions detection for the wastewater determination.
\end{abstract}

\section{Introduction}

Aside from the essential contribution in industry and electrochemistry, the pollutants of heavy metal ions such as copper $\left(\mathrm{Cu}^{2+}\right)$ and lead $\left(\mathrm{Pb}^{2+}\right)$ are still an unresolved issue in the industrial wastewater. Trace $\mathrm{Cu}^{2+}$ and $\mathrm{Pb}^{2+}$ would contaminate the drinking water as well as the bare soil, which would severely have long-term damage effects on human being's brain, heart, kidney, lungs, and other organs. It is reported too much $\mathrm{Cu}^{2+}$ would affect the enzyme activity, and the cell metabolism would also be inhibited by excessive $\mathrm{Cu}^{2+}$ in the human body. And according to the United States Environmental Protection Agency (EPA), the maximum allowable level of $\mathrm{Pb}^{2+}$ in the blood is $0.1 \mathrm{mg} / \mathrm{L}(483 \mathrm{nM})[1,2]$.

To protect human health and the environment, instrument-based assays including the atomic absorption spectrometry (AAS), electrochemical method, and inductively coupled plasma mass spectrometry (ICPMS) have been developed for the analysis detection of heavy metal ions.
However, they have inevitable disadvantages such as the expensive equipment, sophisticated instrumentation, and tedious preparation processes [3, 4]. Nowadays, fluorescent sensors (including quantum dots, organic dyes, metal clusters, and rare-earth nanocrystals) have been widely explored for the detection of the heavy metal ions. Among these fluorescent sensors, carbon dots (CDs) have attracted considerable attentions, owing to their low cytotoxicity, robust chemical inertness, excellent biocompatibility, low photobleaching, and stable photoluminescence (PL) properties [5-8]. Plentiful preparation methods including "bottomup" and "top-down" approaches made great efforts to synthesize the doped-CDs and significantly enhanced their properties to broaden their novel applications [9]. Nitrogen $(\mathrm{N})$ and sulfur (S) are the most commonly doping elements for CDs. With the comparable atomic size (the radius of $\mathrm{C}$ : $0.77 \AA$, N: $0.75 \AA$ ), strong valence bonds, and similar electronegativity (electronegativity of C:2.55, S:2.58), the presence of the $\mathrm{N}$ and $\mathrm{S}$ atoms could produce additional electron pairs, 
new defects sites and the active sites, which would significantly modify the local chemical activities of the carbon nanostructures. In addition, these active sites can induce the electron transfer between the heavy metal ions and the doped-CDs. As it is reported, the doped-CDs have been successfully used in detection of $\mathrm{Pb}^{2+}$ and $\mathrm{Cu}^{2+}$, respectively [10-12].

For the detection of heavy metal ions, many researchers focused on the synthesizing luminescent CDs capable of sensitively and selectively detecting the metal ions, including choosing the green materials as the precursor, doping different elements into the CDs, and optimizing the surface functionalities for chelating with the metal ions [13-16]. The photoluminescence (PL) spectra were commonly utilized for the detection of different heavy metal ions. Based on this method, the previous reports indicated that trace $\mathrm{Cu}^{2+}$ or $\mathrm{Pb}^{2+}$ ions (as low as to nanomole or micromole) would be detected by the various CDs in the aqueous solution [17, 18]. However, for the practical applications, visual one-site detection methods would be recommended for their convenience without any expensive equipment or complex processes. Few groups reported for this method. For example, Liu et al. developed a novel fluorescence test paper for the detection of $\mathrm{Cu}^{2+}$ ions. Under the $365 \mathrm{~nm}$ light, the fluorescence color of the test paper would change from blue to purple with the increasing concentration of $\mathrm{Cu}^{2+}$ ions. This method would be used as the semiquantification of the trace $\mathrm{Cu}^{2+}$ ions ( $\left.25 \mathrm{nM}\right)$ [19]. Ansi and Renuka proposed the colorimetric analysis for $\mathrm{Pb}^{2+}$ ions in water. They prepared the CDs from the table sugar and applied them for the detection of $\mathrm{Pb}^{2+}$ ions. Due to the aggregation of CDs, the precipitated solution of $\mathrm{CDs}+\mathrm{Pb}^{2+}$ ions could easily detected by the naked eye 9 (the detection limit of $67 \mathrm{nM}$ ) [20]. Therefore, the novel visual sensor systems should be developed in the field of water pollution detection.

Herein, a facile hydrothermal method was explored to prepare the N,S codoped CDs (NS-CDs) by using the green and nontoxic L-cysteine as the precursor. The obtained NSCDs exhibited ultrasensitive detection characteristics for $\mathrm{Cu}^{2+}$ and $\mathrm{Pb}^{2+}$ through the PL emission quenching. Apart from the traditional PL detection method, it is also found that the NS-CDs could detect the $\mathrm{Cu}^{2+}$ and $\mathrm{Pb}^{2+}$ ions in aqueous solution directly and sensitively by the colorimetric method without further treatment. And unlike the complicated colorimetric detection process reported previously (for example, the gold nanoparticles functionalized by L-cysteine could detect the metal ions and the whole reaction should be induced by the ultraviolet light) [21], the newly synthesized NS-CDs have the advantages of simple and visual one-site detection for $\mathrm{Pb}^{2+}$ and $\mathrm{Cu}^{2+}$ with potential applications in the heavy ion detection of wastewater.

\section{Experimental}

All the reagents were purchased from Aladdin (Shanghai, China). All chemicals were used as received, without further purification. The ultrapure water used in the whole experiment holds the resistivity no lower than $18.1 \mathrm{M} \Omega \mathrm{cm}$. The $\mathrm{Ca}\left(\mathrm{NO}_{3}\right)_{2} \bullet 4 \mathrm{H}_{2} \mathrm{O}, \mathrm{FeCl}_{3}, \mathrm{~Pb}\left(\mathrm{NO}_{3}\right)_{2}, \quad \mathrm{MgCl}_{2} \bullet 6 \mathrm{H}_{2} \mathrm{O}$,
$\mathrm{Zn}\left(\mathrm{NO}_{3}\right)_{2} \bullet 6 \mathrm{H}_{2} \mathrm{O}, \mathrm{KNO}_{3}, \mathrm{Cu}\left(\mathrm{NO}_{3}\right)_{2} \bullet 3 \mathrm{H}_{2} \mathrm{O}, \quad \mathrm{FeCl}_{2} \bullet 4 \mathrm{H}_{2} \mathrm{O}$, $\mathrm{Na}_{2} \mathrm{CO}_{3}$, and $\mathrm{Al}\left(\mathrm{NO}_{3}\right)_{3} \bullet 9 \mathrm{H}_{2} \mathrm{O}$ were selected as the sources of heavy metal ions, and each solution was confected to the concentration of $20 \mathrm{mmol} / \mathrm{L}$.

\section{Preparation of Samples}

The NS-CDs are synthesized as follows. The mixture of $0.015 \mathrm{~g}$ L-cysteine and $30 \mathrm{ml}$ ultrapure water became a homogeneous solution after a stirring drastically for 10 minutes and was transferred into the Teflon-lined autoclave. After maintained at $190^{\circ} \mathrm{C}$ for 6 hours, the obtained slight green solution was further dialyzed for $8 \mathrm{~h}$ in the dialysis bag with the molecular weight cutoff (MWCO) of $1000 \mathrm{Da}$ against the ultrapure water for purification. And finally, the product was dried through a freezing dryer. A series of metallic salt (including $\mathrm{Ca}^{2+}, \mathrm{Fe}^{2+}, \mathrm{Al}^{3+}, \mathrm{Pb}^{2+}, \mathrm{Mg}^{2+}, \mathrm{Zn}^{2+}, \mathrm{Fe}^{3+}, \mathrm{K}^{+}$, $\mathrm{Cu}^{2+}$, and $\mathrm{Na}^{+}$) solutions were prepared separately and added into the NS-CDs solution for determining the detection properties.

\section{Sample Characterization}

The transmission electron microscopy (TEM) was performed using an F-30 S-TWIN electron microscope (Tecnai G2, FEI Company). A Rigaku D/Max-2400 X-ray diffractometer (XRD) was employed to check the phases of the obtained samples. Deionized water was gained by a Millipore Elix 5 UV and Milli-Q Gradient Ultra-Pure Water System. X-ray photoelectron spectroscopy (XPS, PHI-5702, Physical Electronics) was performed using a monochromated $\mathrm{Al} \mathrm{Ka}$ irradiation. The Fourier transform infrared spectra (FT-IR) of the samples were recorded between 500 and $4000 \mathrm{~cm}^{-1}$ on a FT-IR spectrometer (Nicolet NEXUS 670) using KBr pellets. The photoluminescence (PL) spectra and fluorescence emission spectra were recorded using an FLS-920T fluorescence spectrophotometer and a HORIBA JOBIN YVON Fluorolog-3 Spectrofluorometer system at $16^{\circ} \mathrm{C}$, respectively. Without a particular statement, all the measurements were performed at room temperature.

\section{Results and Discussion}

Just as it revealed in the TEM image NS-CDs (Figure 1(a)), the as-prepared NS-CDs showed an ellipsoid morphology and well-dispersed with a relatively narrow size distribution of 2.1-3.9 nm (Figure 1(b)). The high-resolution TEM (HRTEM) image inset of Figure 1(a) indicated the high crystallinity of the NS-CDs with the lattice spacing of $0.29 \mathrm{~nm}$, corresponding to the (002) spacing of graphitic carbon lattice parameters. For further exploring the statue of elements, XPS use used to probe the NS-CDs. In the high-resolution XPS carbon (C) spectrum (Figure S1), the five peaks at 284.4, $284.9,285.5,286.5$, and $288.7 \mathrm{eV}$ should be attributed to $\mathrm{C}=\mathrm{C}, \mathrm{C}-\mathrm{S}, \mathrm{C}-\mathrm{N}, \mathrm{C}-\mathrm{O}$, and $\mathrm{C}=\mathrm{O}$ groups. The $\mathrm{S} 2 \mathrm{p}$ band could be deconvoluted into two peaks, corresponding to $\mathrm{C}$ S-C 2p 2/3 (163.8 eV) and C-S-C 2p 1/2 (164.9 eV), and the $\mathrm{N}$ band could be divided into two peaks, corresponding to pyrrolic $\mathrm{N}(400.1 \mathrm{eV})$ and $\mathrm{N}-\mathrm{H}(401.5 \mathrm{eV})$, as shown in 


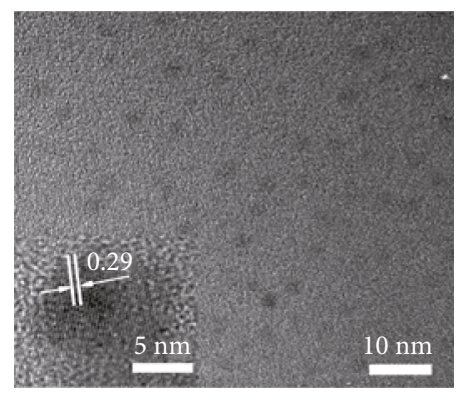

(a)

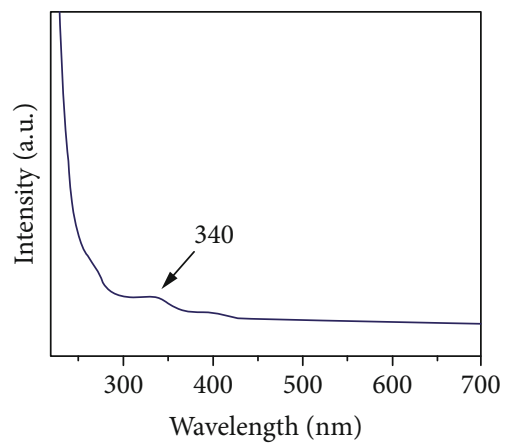

(c)

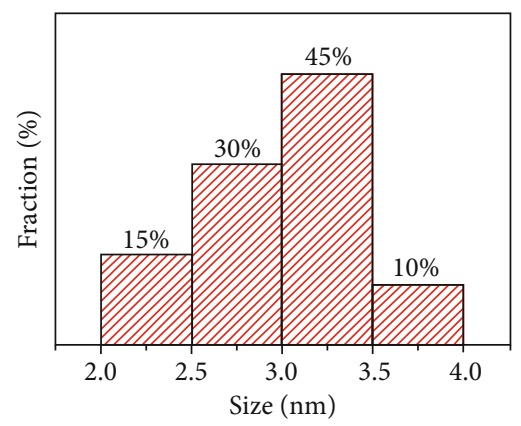

(b)

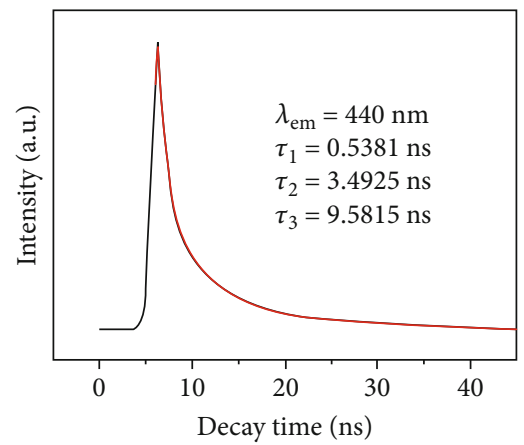

(d)

FIgure 1: (a) The TEM image (the inset is HRTEM image) of the NS-CDs, (b) the particle size distribution of the NS-CDs, (c) the UV-visible absorption, and (d) the luminescence decay curve of NS-CDs, respectively.

Figure S2. Clearly, the N and S atoms were successfully doped and should constitute the main surface functional groups on the NS-CDs.

The UV-vis absorption spectrum (Figure 1(c)) displayed several small absorption bands in the range of $250-400 \mathrm{~nm}$, the band at $270 \mathrm{~nm}$ should be corresponding to the $\pi-\pi^{*}$ transition of the aromatic $\mathrm{sp}^{2}$ domains [22], and the bands at $340 \mathrm{~nm}$ and $400 \mathrm{~nm}$ should be ascribed to the trapping of the excited state energy of the surface states. Various surface states were original from the multiple $\mathrm{N}-, \mathrm{S}-, \mathrm{C}-$, and $\mathrm{O}-$ containing functional groups on the surface of the NS-CDs. The decay curve was recorded for the NS-CDs at $360 \mathrm{~nm}$ by a time-correlated single-photon counting technique, as shown in Figure 1(d). The lifetimes were $\tau_{1}=0.5318 \mathrm{~ns}, \tau_{2}$ $=3.4925 \mathrm{~ns}$, and $\tau_{3}=9.5815 \mathrm{~ns}$ [23].

The PL emission spectra of NS-CDs were shown in Figure 2(a), and the maximum emission peak positions were dependent of the excitation wavelength. The emission peaks slightly shifted to longer wavelengths (from $407 \mathrm{~nm}$ to $450 \mathrm{~nm}$ ) when the excitation wavelength increased from $310 \mathrm{~nm}$ to $390 \mathrm{~nm}$, accompanying with the decreasing PL emission intensity. The maximum emission wavelength is located at $440 \mathrm{~nm}$ with the excitation wavelength of $360 \mathrm{~nm}$. The Commission International de L'Eclairage (CIE) under different excitation wavelength $(310-390 \mathrm{~nm})$ was shown in Figure 2(b), and the CIE coordinate was calculated as $(0.1746,0.1551)$, displaying the area of maximum emission $(440 \mathrm{~nm})$ under the excitation at a wavelength of $360 \mathrm{~nm}$. With the excitation wavelength increasing, the emission position ranged from the blue to blue-green area. The PL behavior might be attributed to the different size distribution and various surface state emissive traps on the surface of NSCDs [24]. The quantum yield (QY) of the NS-CDs was measured according to the method of quinine sulfate [25]. Quinine sulfate diluted by $0.1 \mathrm{M} \mathrm{H}_{2} \mathrm{SO}_{4}$ solution was chosen as the reference standard substance, and the QY was 0.55. The calculation equation of $\mathrm{QY}$ is as follows.

$$
\phi_{x}=\frac{A_{s}}{I_{s}} \cdot \frac{I_{x}}{A_{x}} \cdot \frac{n_{x}^{2}}{n_{s}^{2}} \cdot \phi_{s} \phi_{x}=\frac{A_{s}}{I_{s}} \cdot \frac{I_{x}}{A_{x}} \cdot \frac{n_{x}^{2}}{n_{s}^{2}} \cdot \phi_{s}
$$

The NS-CDs was represented as the subscript " $x$," and the standard substance was represented as the subscript. The " $x$," " $A$," "I," " $n$," and " $\varphi$ " are the absorbance, integrated fluorescent emission intensity, refractive index, and the QY. Based on the calculation with quinine sulfate as the standard substance, the QY value of the NS-CDs is $18 \%$.

The stability of CDs is very important for their practical application. Then, the fluorescent stability of NS-CDs was examined for a wide range of postheat treatment temperature $\left(30 \sim 90^{\circ} \mathrm{C}\right)$ at fixed temperature for $2 \mathrm{~h}$. The PL emission spectra were shown in the supporting information (Figure S3). The maximum emission intensity at $440 \mathrm{~nm}$ slightly increased upon raising the heat treatment temperature from 30 to $90^{\circ} \mathrm{C}$, and the phenomena would be attributed to the recovery of partial surface defects. The result is similar to the reported $\mathrm{N}$-doped CDs prepared by 


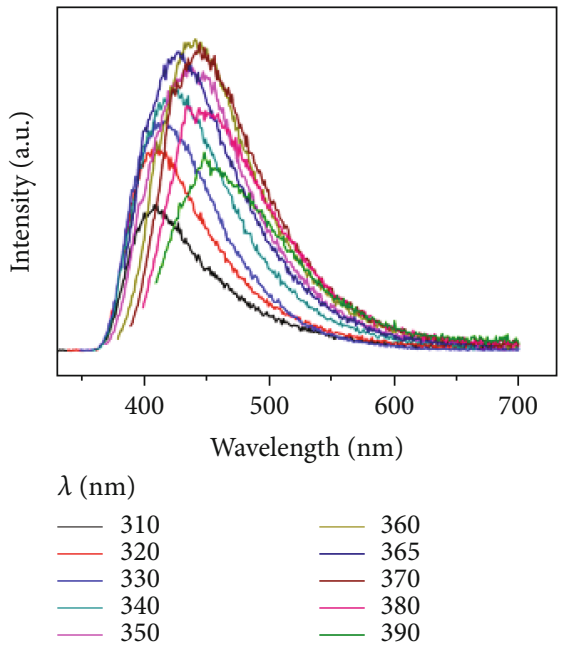

(a)

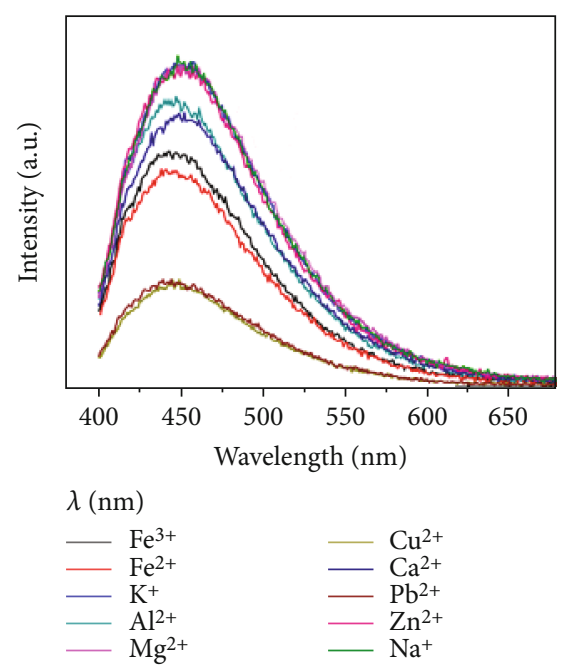

(c)

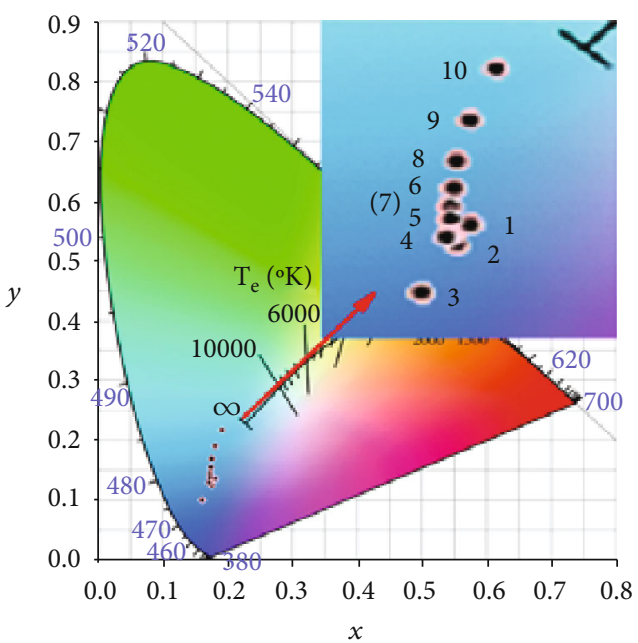

(b)

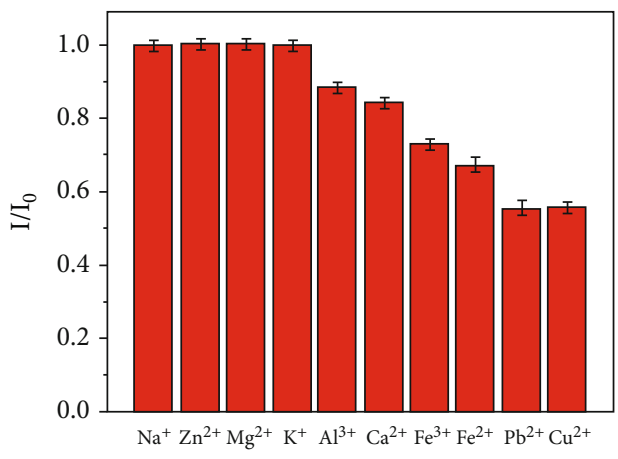

(d)

Figure 2: (a) The PL emission spectra and (b) the CIE chromaticity coordinates of NS-CDs under different excitation wavelengths (from 310 to $390 \mathrm{~nm}$ ). (c) The emission spectra and (d) the corresponding PL intensity ratio (I/Io) for NS-CDs mixing with different heavy metal ions.

using ammonium citrate and urea as the precursors [26]. The as-prepared CDs exhibited excellent thermal stability.

To investigate the sensing specificity of NS-CDs, we measured the PL responses to ten common metal ions such as $\mathrm{Na}^{+}, \mathrm{Zn}^{2+}, \mathrm{Mg}^{2+}, \mathrm{K}^{+}, \mathrm{Al}^{3+}, \mathrm{Ca}^{2+}, \mathrm{Fe}^{3+}, \mathrm{Fe}^{2+}, \mathrm{Pb}^{2+}$, and $\mathrm{Cu}^{2+}$ $(20 \mathrm{mM})$ for the fixed incubation time of $5 \mathrm{~min}$, as shown in Figure 2(c). It is found that the as-prepared NS-CDs exhibited sensitive detection property for $\mathrm{Pb}^{2+}$ and $\mathrm{Cu}^{2+}$ by the substantial PL emission quenching effect. For the other ions, the existence of the $\mathrm{Na}^{+}, \mathrm{Zn}^{2+}, \mathrm{Mg}^{2+}$, and $\mathrm{K}^{+}$ions had almost no influence on the PL intensity of NS-CDs, while the PL was slightly quenched in the presence of $\mathrm{Al}^{3+}, \mathrm{Ca}^{2+}, \mathrm{Fe}^{3+}$, and $\mathrm{Fe}^{2+}$ ions. Compared with the above metal ions, it was indicated that $\mathrm{Cu}^{2+}$ and $\mathrm{Pb}^{2+}$ ions could effectively quench the
PL emission of NS-CDs. The absorption spectra and the decay curves of NS-CDs, dots $+\mathrm{Cu}^{2+}$, and dots $+\mathrm{Pb}^{2+}$ ions are shown in Figure S4. For the $\mathrm{Cu}^{2+}$ ion detection, the quenching process should be related to the static quenching mechanism, which means that a nonfluorescent groundstate complex formed through the interaction between NS$\mathrm{CDs}$ and the quencher ( $\mathrm{Cu}^{2+}$ ions). And this quenching is accompanied with the change of the absorption spectrum of the NS-CDs as well as the almost unchanged average fluorescence lifetime ( $\tau$ was $2.98 \mathrm{~ns}$ for NS-CDs and $3.04 \mathrm{~ns}$ for dots $\left.+\mathrm{Cu}^{2+}\right)$. The quenching mechanism was similar to the previous report of the quenching of $\mathrm{Cu}^{2+}$ ions by the CDs prepared from thiourea and diethylene glycol via microwave irradiation [27]. While for the detection of $\mathrm{Pb}^{2+}$ 


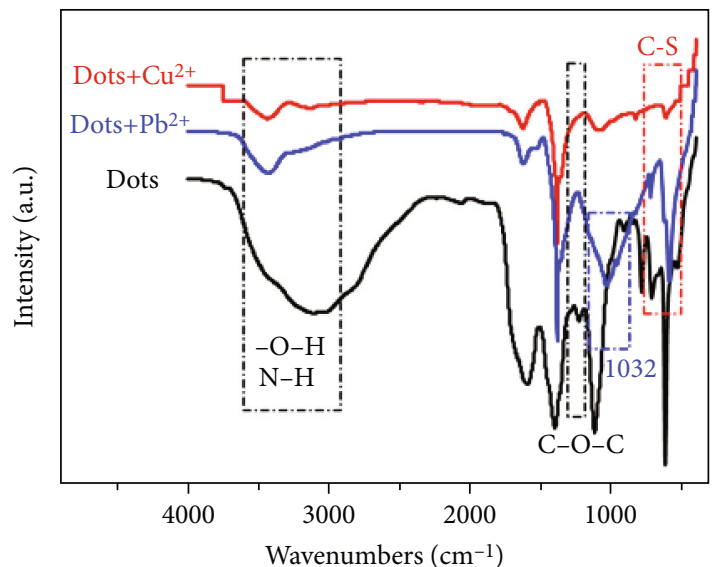

(a)

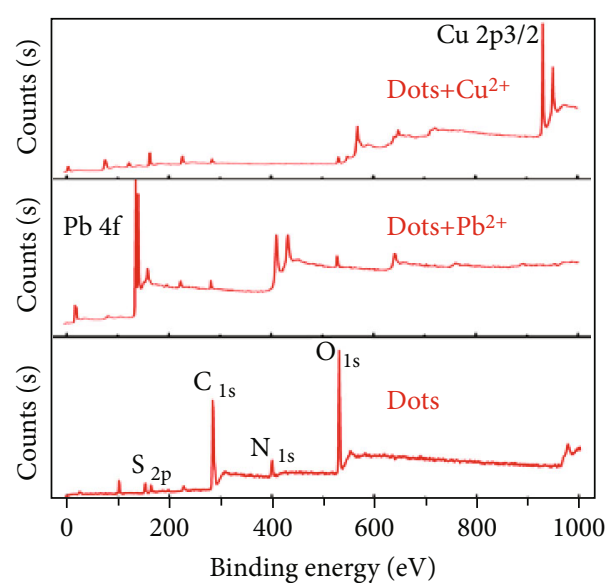

(b)

Figure 3: (a) The FTIR and (b) XPS spectra for NS-CDs dots $+\mathrm{Cu}^{2+}$ and dots $+\mathrm{Pb}^{2+}$.

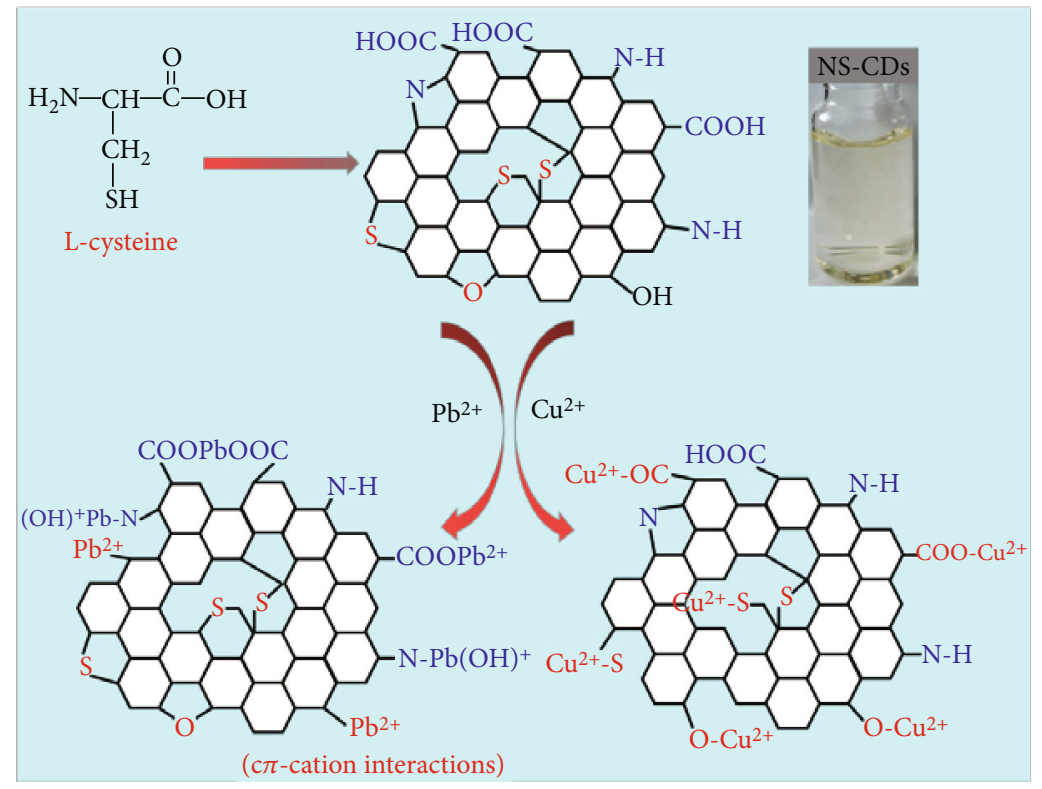

Figure 4: Schematic presentation of formation NS-CDs and the binding mechanism with $\mathrm{Cu}^{2+}$ and $\mathrm{Pb}^{2+}$ ions.

ions, the change of the absorption spectrum was also observed. After fitting the decay curve, a new and short $\tau$ ( $0.0567 \mathrm{~ns})$ appeared, and the other $\tau$ values were similar to that of NS-CDs. The calculated average fluorescence lifetime decreased to $2.79 \mathrm{~ns}$. Therefore, static quenching and dynamic quenching process could be coexisted for the $\mathrm{Pb}^{2+}$ quenching mechanism. The new $\tau$ component would be related to the dynamic quenching process, which means that the excited state of NS-CDs would return to the ground state by the collision between the $\mathrm{Pb}^{2+}$ ions and NS-CDs by energy transfer or charge transfer [28].

To further investigate the coordination interactions between NS-CDs with the $\mathrm{Cu}^{2+}$ and $\mathrm{Pb}^{2+}$ ions, the FT-IR spectra of the pristine NS-CDs, dots $+\mathrm{Cu}^{2+}$, and dots $+\mathrm{Pb}^{2+}$ samples were measured to detect the changes of the stretching vibrations of the functional groups, as shown in
Figure 3(a). The stretching vibrations of $\mathrm{O}-\mathrm{H}$ and $\mathrm{N}-\mathrm{H}$ in the NS-CDs were distinctively observed by the broadband from $3185 \mathrm{~cm}^{-1}$ to $3440 \mathrm{~cm}^{-1}$. Contrarily, after coordinated with $\mathrm{Cu}^{2+}$ or $\mathrm{Pb}^{2+}$ ions, the vibration band of the $\mathrm{O}-\mathrm{H}$ and $\mathrm{N}-\mathrm{H}$ shifted to long wavenumbers and narrowed, suggesting the cheating effects of $\mathrm{Cu}^{2+}$ or $\mathrm{Pb}^{2+}$ ions with these functional groups on the NS-CDs [29]. The stretching vibrations of C$\mathrm{O}-\mathrm{C}$ in the dots $+\mathrm{Cu}^{2+}$ and dots $+\mathrm{Pb}^{2+}$ disappeared (at $\left.1240 \mathrm{~cm}^{-1}\right)$. For dots $+\mathrm{Cu}^{2+}$, the changes of the peaks at $600 \mathrm{~cm}^{-1}$ and $727 \mathrm{~cm}^{-1}$ revealed the combination between the $\mathrm{Cu}^{2+}$ ions and $\mathrm{C}-\mathrm{S}$ groups. For dots $+\mathrm{Pb}^{2+}$, the pyridine-, pyridine-N-O-, and/or pyridine-like peaks at $1125 \mathrm{~cm}^{-1}$ shifted to $1032 \mathrm{~cm}^{-1}$, which was related to bind with $\mathrm{Pb}^{2+}$ ions [30].

We also compared the XPS spectra of pristine NS-CDs, dots $+\mathrm{Cu}^{2+}$, and dots $+\mathrm{Pb}^{2+}$ samples, as shown in Figure 3(b). 


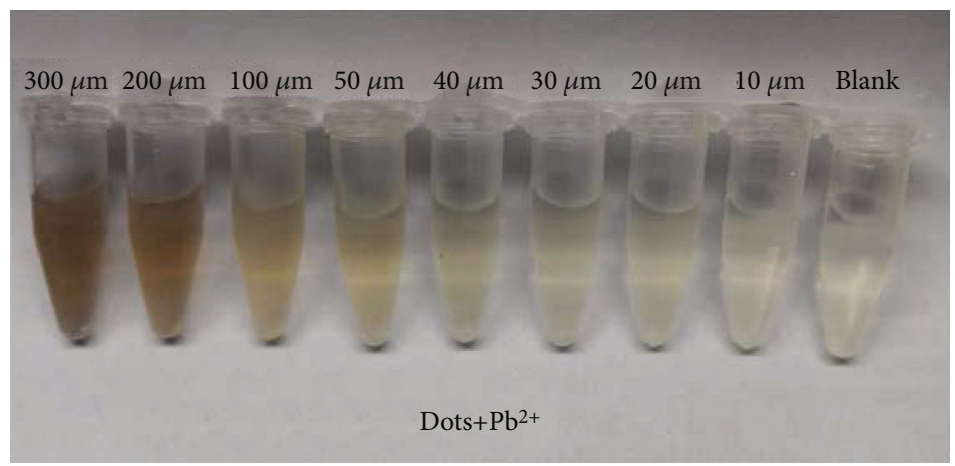

(a)

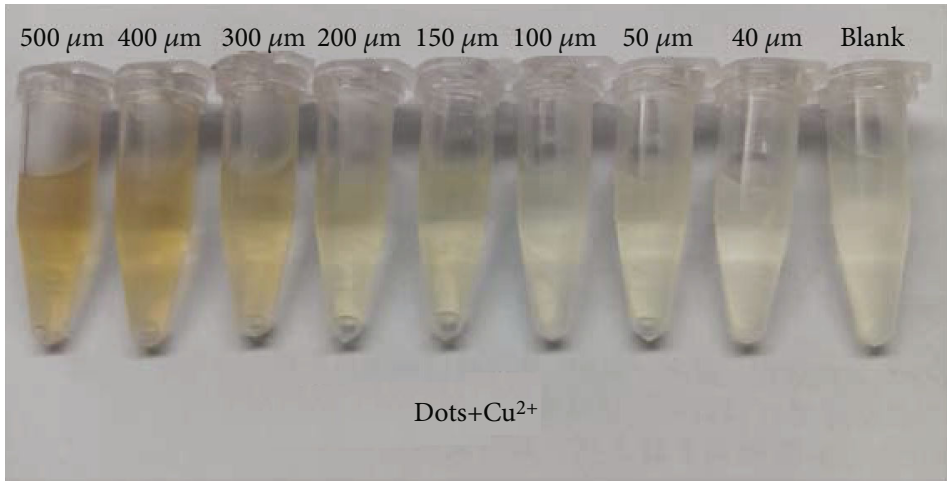

(b)

Figure 5: The photos of NS-CDs with different concentrations of (a) $\mathrm{Pb}^{2+}$ and (b) $\mathrm{Cu}^{2+}$.

It should be noted that the main state of copper was $\mathrm{Cu} 2 \mathrm{p} 3 / 2$ state at $932.0 \mathrm{eV}$, which were frequently connected to the coordination between $\mathrm{Cu}$ and $\mathrm{S} / \mathrm{O}$-related groups, and the nextdoor peak at $954.0 \mathrm{eV}$ corresponded to the $\mathrm{Cu} 2 \mathrm{p} 1 / 2$ state $[31,32]$. There were also observed the small peak at $161.5 \mathrm{eV}$, which represented the existence of $\mathrm{Cu}-\mathrm{S}$ bonds. As shown in Figure S5(a), the II peak at $532.2 \mathrm{eV}$ should demonstrate the presence of $\mathrm{Cu}-\mathrm{O}$ bonds [33]. The full spectrum of dots $+\mathrm{Pb}^{2+}$ displayed that lead mainly existed in the state of $\mathrm{Pb} 4 \mathrm{f}$ in the range of $135-140 \mathrm{eV}$. The $138.5 \mathrm{eV}$ band was assigned to $\mathrm{Pb}$ species adsorbed with the oxygenand/or nitrogen-containing groups of the NS-CDs, while the $140.0 \mathrm{eV}$ should be related to $\mathrm{Pb}^{2+}$ adsorbed on the NS-CDs surface as the Lewis centers or p-electrons-cation interactions. What is more, the peaks at $412.0 \mathrm{eV}, 434.3 \mathrm{eV}$, and $643.6 \mathrm{eV}$ were assigned to the $\mathrm{Pb} 4 \mathrm{~d}^{5}, \mathrm{~Pb} 4 \mathrm{~d}^{3}$, and $\mathrm{Pb}$ $4 \mathrm{p}^{3}$ states, respectively. As shown in Figure S5(b), the peaks at $529.1 \mathrm{eV}$ and $530.1 \mathrm{eV}$ in the high resolution of $\mathrm{O} 1 \mathrm{~s}$ of dots $+\mathrm{Pb}^{2+}$ revealed that the oxygen was mainly in the state of $-\mathrm{C}=\mathrm{O}$ (carboxyl). It might be inferred that the coupling of the $\mathrm{Pb}^{2+}$ and NS-CDs was in the following ways of $(=\mathrm{C}$ $\mathrm{COO})_{2} \mathrm{~Pb},=\mathrm{C}-\mathrm{COOPb}^{+},=\mathrm{N}-\mathrm{Pb}(\mathrm{OH})^{+}$, and $\equiv \mathrm{C}^{-} \mathrm{Pb}^{2+}(\mathrm{C} \pi$ -cation interactions) [34]. Figure 4 gave the possible schematic illustration of the NS-CDs and its interaction with $\mathrm{Cu}^{2+}$ or $\mathrm{Pb}^{2+}$ ions.

In addition to the PL detection mentioned above, the fast, portable, and on-site colorimetric method had also been applied in detecting $\mathrm{Cu}^{2+}$ and $\mathrm{Pb}^{2+}$ ions. This method required no equipment and only used the naked eye recognition by the color change. The follow-up experiments were designed to evaluate the detectable concentration of $\mathrm{Cu}^{2+}$ and $\mathrm{Pb}^{2+}$ ions in the solution of NS-CDs by the change of color (Figure 5). It was reasonable to take the high sensitivity and fast response advantages to determine the specific $\mathrm{Cu}^{2+}$ and $\mathrm{Pb}^{2+}$ ions by means of the color variance. $\mathrm{Cu}^{2+}$ and $\mathrm{Pb}^{2+}$ ions produced the visual color response (from colorless to thin yellow for $\mathrm{Cu}^{2+}$ and to brown for $\mathrm{Pb}^{2+}$ ) after being added into the NS-CDs aqueous solution, while for other metal ions, the solution did not have a noticed color change. For the $\mathrm{Cu}^{2+}$ ions (the concentration range was $0-500 \mu \mathrm{M}$, Figure 5(b)), the minimum observable concentration was $50 \mu \mathrm{M}$, and the detection degree could reach as high as the result obtained by the reported gold nanoparticles previously [21]. The minimum detection concentration of $\mathrm{Pb}^{2+}$ ions was lower than that of $\mathrm{Cu}^{2+}$ ions $(20 \mu \mathrm{M}$, Figure 5(a)). And when the concentration of $\mathrm{Pb}^{2+}$ ions was less than $20 \mu \mathrm{M}$, no observable change was observed, and it could be considered as the detectable minimum concentration of $\mathrm{Pb}^{2+}$ by the colorimetric method.

\section{Conclusion}

In summary, NS-CDs were prepared by using the L-cysteine as the precursor via a feasible hydrothermal method. The asprepared NS-CDs revealed the efficient detectability for $\mathrm{Pb}^{2+}$ and $\mathrm{Cu}^{2+}$ by the PL quenching detection as well as the colorimetric method. The analysis of the FT-IR and XPS spectra of the precipitate revealed that the $\mathrm{Cu}-\mathrm{O}$ and $\mathrm{Cu}-\mathrm{S}$ bonds were mainly coordination styles for $\mathrm{Cu}^{2+}$ ions on the NS-CDs, while for $\mathrm{Pb}^{2+}$ ions, they would prefer to connect to the 
NS-CDs in the forms of $=\mathrm{C}-(\mathrm{COO})_{2} \mathrm{~Pb},=\mathrm{C}-\mathrm{COOPb}^{+},=\mathrm{N}-$ $\mathrm{Pb}(\mathrm{OH})^{+}$, and $\equiv \mathrm{C}: \mathrm{Pb}^{2+}(\mathrm{C} \pi$-cation interactions $)$. With a specific and sensitive detectable property, the NS-CDs exhibited an irreplaceable application in the wastewater determination in the industry and environmental monitoring.

\section{Data Availability}

All data generated or analyzed during this study are included in this article.

\section{Conflicts of Interest}

The authors declare that they have no conflicts of interest.

\section{Authors' Contributions}

Hui Gao and Yuqian Pang contributed equally to this work.

\section{Acknowledgments}

This work was financially supported by the National Science Foundation of Gansu Province (18JR3RA269), the National Natural Science Foundation of China (61378037), the National First-class Discipline Program of Food Science and Technology (JUFSTR20180302), and the National Key Research and Development Program of China (2018YFC1604204, 2018YFD0400402).

\section{Supplementary Materials}

Figure S1. The high resolution C 1s XPS spectrum for NSCDs. Figure S2. The high resolution spectra of (a) S 2p XPS and (b) N 1s XPS for NS-CDs. Figure S3. (a) The PL emission spectra and (b) the ratio of $\mathrm{I} / \mathrm{I}_{\mathrm{o}}$ of NS-CDs under different heat treatment temperature for $2 \mathrm{~h}$. Figure S4. (a) The UVVis absorption spectra and (b) the luminescence decay spectra of NS-CDs, dots $+\mathrm{Cu}^{2+}$ and dots $+\mathrm{Pb}^{2+}$. (Supplementary Materials)

\section{References}

[1] Y. Huang, Y. Ma, Y. Chen et al., "Target-responsive DNAzyme cross-linked hydrogel for visual quantitative detection of lead," Analytical Chemistry, vol. 86, no. 22, pp. 11434-11439, 2014.

[2] J. Xu, J. Pan, Y. Zhang, J. Liu, L. Zeng, and X. Liu, "Ultrasensitive near-infrared fluorescence-enhanced probe for discriminative detection of GSH and Cys from different emission channels," Sensors and Actuators B: Chemical, vol. 238, pp. 58-65, 2017.

[3] T. Poursaberi, L. Hajiagha-Babaei, M. Yousefi et al., "The synthesis of a new thiophene-derivative Schiff's base and its use in preparation of copper-ion selective Electrodes," Electroanalysis, vol. 13, no. 18, pp. 1513-1517, 2001.

[4] J. Zhang, Y. Zhou, J. Yoon, and J. S. Kim, "Recent progress in fluorescent and colorimetric chemosensors for detection of precious metal ions (silver, gold and platinum ions)," Chemical Society Reviews, vol. 40, no. 7, pp. 3416-3429, 2011.

[5] Y. Pang, H. Gao, S. Wu, and X. Li, "Facile synthesis the nitrogen and sulfur co-doped carbon dots for selective fluorescence detection of heavy metal ions," Materials Letters, vol. 193, pp. 236-239, 2017.

[6] Z. Wang, X. Yu, F. Li et al., "Preparation of boron-doped carbon dots for fluorometric determination of $\mathrm{Pb}(\mathrm{II}), \mathrm{Cu}(\mathrm{II})$ and pyrophosphate ions," Microchimica Acta, vol. 184, no. 12, pp. 4775-4783, 2017.

[7] Q. Xu, W. Li, L. Ding, W. Yang, H. Xiao, and W. J. Ong, "Function-driven engineering of $1 \mathrm{D}$ carbon nanotubes and $0 \mathrm{D}$ carbon dots: mechanism, properties and applications," Nanoscale, vol. 11, no. 4, pp. 1475-1504, 2019.

[8] Y. Liu, J. Wei, X. Yan, M. Zhao, C. Guo, and Q. Xu, "Barium Charge Transferred Doped Carbon Dots with Ultra-High Quantum Yield Photoluminescence of 99.6\% and Applications," Chinese Chemical Letters, 2020, in press.

[9] A. Gupta, N. C. Verma, S. Khan, S. Tiwari, A. Chaudhary, and C. K. Nandi, "Paper strip based and live cell ultrasensitive lead sensor using carbon dots synthesized from biological media," Sensors and Actuators B: Chemical, vol. 232, pp. 107-114, 2016.

[10] S. Zhang, Q. Wang, G. Tian, and H. Ge, “A fluorescent turnoff/on method for detection of $\mathrm{Cu}^{2+}$ and oxalate using carbon dots as fluorescent probes in aqueous solution," Materials Letters, vol. 115, pp. 233-236, 2014.

[11] D. Sun, R. Ban, P. Zhang, G. Wu, J. Zhang, and J. Zhu, "Hair fiber as a precursor for synthesizing of sulfur-and nitrogenco-doped carbon dots with tunable luminescence properties," Carbon, vol. 64, pp. 424-434, 2013.

[12] F. Wang, Z. Gu, W. Lei, W. Wang, X. Xia, and Q. Hao, "Graphene quantum dots as a fluorescent sensing platform for highly efficient detection of copper (II) ions," Sensors and Actuators B: Chemical, vol. 190, pp. 516-522, 2014.

[13] K. K. Chan, S. H. K. Yap, and K.-T. Yong, "Biogreen synthesis of carbon dots for biotechnology and nanomedicine applications," Nano-Micro Letters, vol. 10, no. 4, p. 72, 2018.

[14] P. Devi, P. Rajput, A. Thakur, K.-H. Kim, and P. Kumar, "Recent advances in carbon quantum dot-based sensing of heavy metals in water," Trends in Analytical Chemistry, vol. 114, pp. 171-195, 2019.

[15] X. Gao, C. Du, Z. Zhuang, and W. Chen, "Carbon quantum dot-based nanoprobes for metal ion detection," Journal of Materials Chemistry C, vol. 4, no. 29, pp. 6927-6945, 2016.

[16] G. Gao, Y. Jiang, H. Jia, J. Yang, and F. Wu, “On-off-on fluorescent nanosensor for $\mathrm{Fe}^{3+}$ detection and cancer/normal cell differentiation via silicon-doped carbon quantum dots," Carbon, vol. 134, pp. 232-243, 2018.

[17] D. Chen, M. Xu, W. Wu, and S. Li, "Multi-color fluorescent carbon dots for wavelength-selective and ultrasensitive $\mathrm{Cu}^{2+}$ sensing," Journal of Alloys and Compounds, vol. 701, pp. 7581, 2017.

[18] Y. Liu, Q. Zhou, Y. Yuan, and Y. Wu, "Hydrothermal synthesis of fluorescent carbon dots from sodium citrate and polyacrylamide and their highly selective detection of lead and pyrophosphate," Carbon, vol. 115, pp. 550-560, 2017.

[19] C. Liu, D. Ning, C. Zhang et al., "Dual-colored carbon dot ratiometric fluorescent test paper based on a specific spectral energy transfer for semiquantitative assay of copper ions," ACS Applied Materials and Interfaces, vol. 9, no. 22, pp. 18897-18903, 2017.

[20] V. Ansi and N. Renuka, "Table sugar derived carbon dot - a naked eye sensor for toxic $\mathrm{Pb}^{2+}$ ions," Sensors and Actuators B: Chemical, vol. 264, pp. 67-75, 2018. 
[21] F. Chai, C. Wang, T. Wang, Z. Ma, and Z. Su, "L-cysteine functionalized gold nanoparticles for the colorimetric detection of $\mathrm{Hg}^{2+}$ induced by ultraviolet light," Nanotechnology, vol. 21, no. 2, p. 025501, 2010.

[22] Y. Dong, J. Shao, C. Chen et al., "Blue luminescent graphene quantum dots and graphene oxide prepared by tuning the carbonization degree of citric acid," Carbon, vol. 50, no. 12, pp. 4738-4743, 2012.

[23] X. Li, S. P. Lau, L. Tang, R. Ji, and P. Yang, "Sulphur doping: a facile approach to tune the electronic structure and optical properties of graphene quantum dots," Nanoscale, vol. 6, no. 10, pp. 5323-5328, 2014.

[24] R. Zhang, J. R. Adsetts, Y. Nie, X. Sun, and Z. Ding, “Electrochemiluminescence of nitrogen- and sulfur-doped graphene quantum dots," Carbon, vol. 129, pp. 45-53, 2018.

[25] D. Sun, R. Ban, P. Zhang, G. Wu, J. Zhang, and J. Zhu, "Hair fiber as a precursor for synthesizing of sulfur- and nitrogenco-doped carbon dots with tunable luminescence properties," Carbon, vol. 64, pp. 424-434, 2013.

[26] W. U. Khan, D. Wang, and Y. Wang, "Highly green emissive nitrogen-doped carbon dots with excellent thermal stability for bioimaging and solid-state LED," Inorganic Chemistry, vol. 57, no. 24, pp. 15229-15239, 2018.

[27] L. Wang, Y. Bi, J. Gao, Y. Li, H. Ding, and L. Ding, "Carbon dots based turn-on fluorescent probes for the sensitive determination of glyphosate in environmental water samples," RSC Advances, vol. 6, no. 89, pp. 85820-85828, 2016.

[28] F. Zu, F. Yan, Z. Bai et al., "The quenching of the fluorescence of carbon dots: a review on mechanisms and applications," Microchimica Acta, vol. 184, no. 7, pp. 1899-1914, 2017.

[29] K. Qu, J. Wang, J. Ren, and X. Qu, “Carbon dots prepared by hydrothermal treatment of dopamine as an effective fluorescent sensing platform for the label-free detection of iron (III) ions and dopamine," Chemistry - A European Journal, vol. 19, no. 22, pp. 7243-7249, 2013.

[30] H. Sun, N. Gao, L. Wu, J. Ren, W. Wei, and X. Qu, "Highly photoluminescent amino-functionalized graphene quantum dots used for sensing copper ions," Chemistry - A European Journal, vol. 19, no. 40, pp. 13362-13368, 2013.

[31] Z. Qian, J. Ma, X. Shan, H. Feng, L. Shao, and J. Chen, "Highly luminescent $\mathrm{N}$-doped carbon quantum dots as an effective multifunctional fluorescence sensing platform," Chemistry A European Journal, vol. 20, no. 8, pp. 2254-2263, 2014.

[32] S. Zheng, J. Hu, L. Zhong, W. Song, L. Wan, and Y. Guo, "Introducing dual functional CNT networks into $\mathrm{CuO}$ nanomicrospheres toward superior electrode materials for lithium-ion batteries," Chemistry of Materials, vol. 20, no. 11, pp. 3617-3622, 2008.

[33] J. Chen, J. Xu, S. Zhou, N. Zhao, and C. Wong, "Facile and scalable fabrication of three-dimensional $\mathrm{Cu}(\mathrm{OH}) 2$ nanoporous nanorods for solid-state supercapacitors," Journal of Materials Chemistry A, vol. 3, no. 33, pp. 17385-17391, 2015.

[34] A. Swiatkowski, M. Pakula, S. Biniak, and M. Walczyk, "Influence of the surface chemistry of modified activated carbon on its electrochemical behaviour in the presence of lead (II) ions," Carbon, vol. 42, no. 15, pp. 3057-3069, 2004. 